\title{
Design of farm winery façades for the optimisation of indoor natural lighting: a case study
}

\author{
Daniele Torreggiani, Valentina Corzani, Stefano Benni, Patrizia Tassinari \\ Department of Agricultural Sciences, University of Bologna, Italy
}

\begin{abstract}
This paper deals with the theme of daylighting performances of rural buildings, within a broader research context aimed at establishing design criteria for farm wineries. The objective is to benchmark the performances of different window systems in order to define design guidelines directed towards the optimisation of natural lighting to improve visual comfort and reduce energy consumption. A winegrowing and producing farm with standard features in the EmiliaRomagna region, Northern Italy, is considered as a case study. Particular attention was given to the part of the building designated for tasting activities. The study considered several opening solutions in the building envelope, and showed the effectiveness of those involving south façade glazing with appropriate screening systems. Further analyses will aim to investigate the performance of windows distributed on several fronts, including heat balance assessment.
\end{abstract}

\section{Introduction}

\section{Study objectives}

In recent decades, there has been a greater awareness of the need to reduce the impact on the environment of various production and processing activities, including also the agro-industrial sector (Khana and Hanjrab, 2009). This has led many scholars to focus on the quantitative analysis of energy and water consumption. The strategic objective of maximising energy efficiency and environmen-

\footnotetext{
Correspondence: Daniele Torreggiani, Department of Agricultural Sciences, University of Bologna, viale G. Fanin 48, 40127 Bologna, Italy.

Tel. +39.051.2096196 - Fax: +39.051.2096171.

E-mail: daniele.torreggiani@unibo.it

Key words: winery, modelling simulation, daylighting, building performance.

Received for publication: 20 November 2012.

Accepted for publication: 24 April 2013.

CC Copyright D. Torreggiani et al., 2013

Licensee PAGEPress, Italy

Journal of Agricultural Engineering 2013; XLIV:e3

doi:10.4081/jae.2013.e3
}

This article is distributed under the terms of the Creative Commons Attribution Noncommercial License (by-nc 3.0) which permits any noncommercial use, distribution, and reproduction in any medium, provided the original author(s) and source are credited. tal performance of production processes is extremely important for the wine industry in which there has been input from several disciplines to create integrated approaches to sustainable design (Niccolucci et al., 2008) and define specific self-assessment tools to support it (BEST-Winery: Benchmarking and Energy and Water Efficiency Savings Tool, Lawrence Berkeley National Laboratory, 2005. http://best-winery.lbl.gov; Amethyst: project co-financed by the European Commission with the participation of Italy, France, Spain and Germany, for the development and dissemination of a tool for self-evaluation of winery energy and water efficiency, adopted in Italy in 2008. http://www.amethyst-project.eu). The research study Wineries of the Future (Commonwealth of Australia, 2003) showed that $60-70 \%$ of $\mathrm{CO}_{2}$ emissions from the activities of the wineries surveyed are attributable to electricity consumption, and an average 8$20 \%$ of this is related only to lighting. Advanced analysis methodologies for building fronts aiming to optimise energy consumption for lighting and to improve visual comfort in building design have already been tested in museums (Chang-Sung and Seung-Jin, 2011), schools (Pereza and Guedi Capeluto, 2006), offices (Reinhart and Herkel, 2000) and houses. For these, shading systems (Hussain and Amneh, 2010) and different types of glass (Breitenbach et al., 2001) have been investigated, also using dynamic simulation procedures (Aghemo et al., 2008). Despite the well-known benefits of natural light on the perception and tasting of wine (Oberfeld et al., 2009), and on the visual comfort of visitors and workers, there has been little specific research into agro-industrial buildings and, in particular, into those used for wine production. This paper, part of a wider ongoing research aimed at defining specific design criteria for small and medium-sized wine-growing and producing farms (Torreggiani et al., 2011), provides a comparative performance analysis of different window systems in order to formulate useful design guidelines for the exploitation of natural lighting to improve indoor visual comfort. This means obtaining minimum levels of lighting, glare control and reducing the energy consumption related to artificial lighting methods.

\section{Materials and methods}

The research focusses on a study area in the Emilia-Romagna region, Northern Italy, described and analysed in detail by Tassinari $e t$ al. (2011). This paper refers to a case study that is considered to be significant, within the broader research context mentioned above, for the development of innovative design solutions for new construction and rehabilitation of several buildings of the farmstead. The study examines a farm winery that is representative of the wine-growing and producing sector in this area, with a processing capacity of 400 tons of grapes per year. In particular, we refer to a new building designed within a project of farm optimisation to accommodate the storage of the finished product and receive visitors (Figure 1). 
Attention is focussed on the functional space intended for selling and tasting which have been the subject of specific analyses by the authors in previous studies: the close relationship of this space to the wine production facilities calls for an integrated design (Tassinari et al., 2013) both for the building itself and for the farmyard as a whole (Tassinari $e t$ al., 2010). Today, there is an increasing awareness of the multi-faceted profile of agriculture and facilities to welcome visitors play a crucial role in marketing and promoting a farm image. This requires a renewed focus on functional, architectural and landscape design.

The selling and tasting units of the winery building under study measure $8.80 \mathrm{~m}$ along the east-west axis and $10 \mathrm{~m}$ along the north-south axis, with eave height $4.80 \mathrm{~m}$ and a gabled roof with a $25 \%$ slope. Six envelope solutions have been developed, analysed and compared. A first solution (A) has openings of the same size evenly distributed on all the four sides, with a total lighting area equal to $1 / 8$ of the wall surface (minimum value set out in the health and building regulations in force). This solution is compared with four variants (B-E) that share the full opening of the southern front and the complete closure of the other sides (Figures 2 and 3 ). An envelope designed to have the complete opening of a front is particularly appropriate to establish a relationship and interaction between building interiors and exteriors. For example, this is possible through the arrangement of exhibition spaces, and this becomes particularly important for visitors in cases in which the opening offers a view of the farm vineyards. While solution (B) provides no shield on the south wall, the other solutions (C-E) have different systems to direct sunlight designed to minimise glare and prevent direct radiation: (C) maintains a $25 \%$ pitch angle, extending coverage with a projection of $1.5 \mathrm{~m}$; (D) has fixed horizontal shadings oriented at $30^{\circ}$ with respect to the horizontal plane, $0.25 \mathrm{~m}$ wide $\times 0.06$ thick with a $0.3 \mathrm{~m}$ step; (E) has fixed vertical blinds

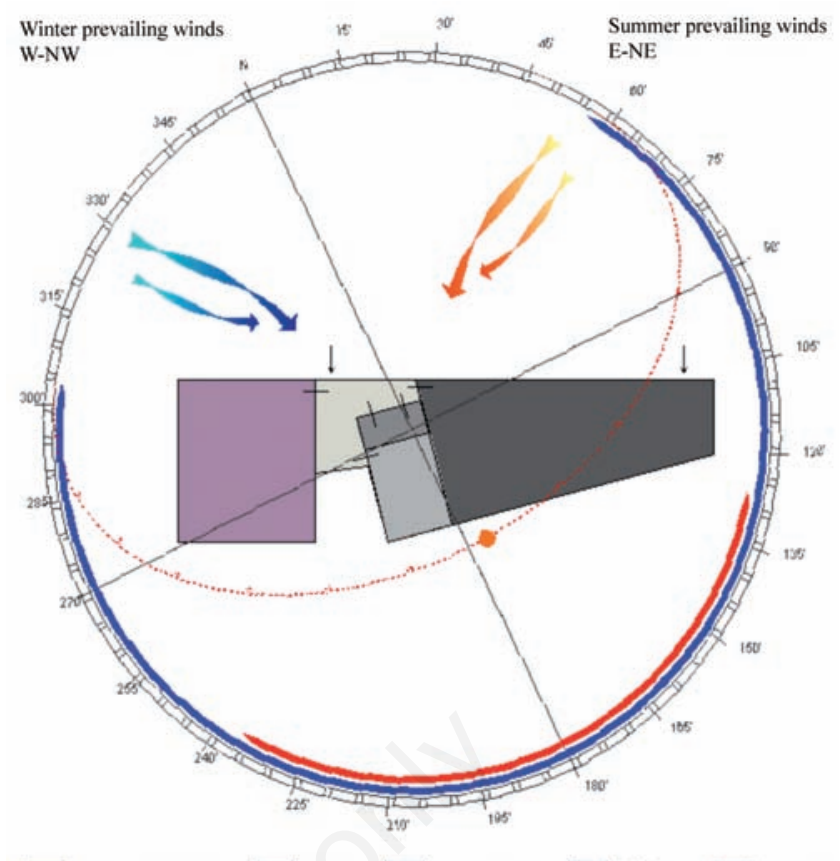

Selling and tasting $\square$ Hall $\square$ Visitors' toilet $\square$ offices $\square$ Storage

Figure 1. Functional layout of the building designed for wine storage and welcoming customers, with annual wind and sun diagrams. The blue and red lines show the winter and summer sun paths, respectively. The orange dotted line shows the daily sun path on June $21^{\text {st }}$ (summer solstice).
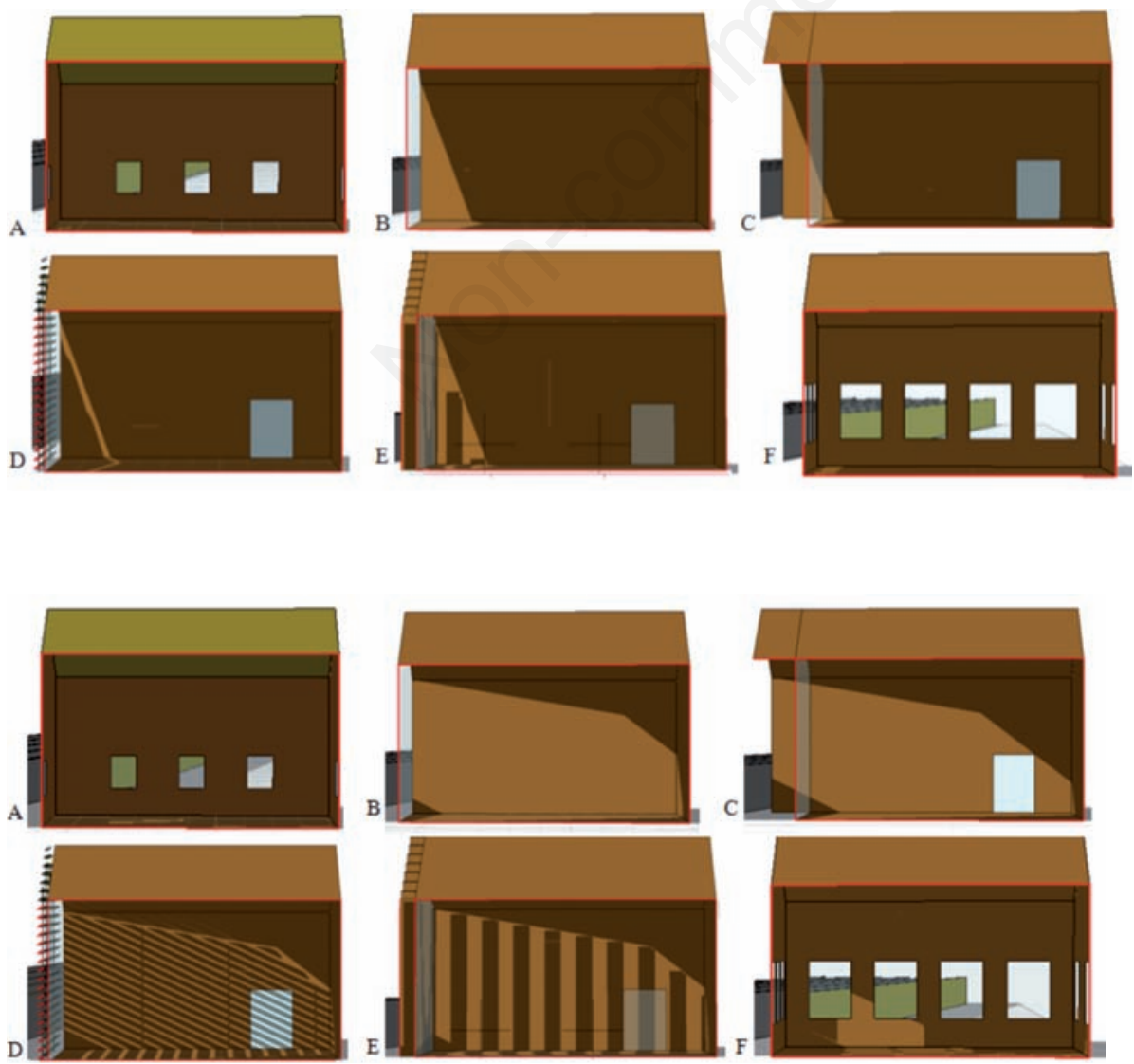

Figure 2. Longitudinal sections (length $10 \mathrm{~m}$ ) of the 6 façade solutions with shadows calculated at 12 noon on June $21^{\text {st }}$ (summer solstice). Surrounding vineyards considered in the simulations are shown in the background.
Figure 3. Longitudinal sections (length $10 \mathrm{~m}$ ) of the 6 façade solutions with shadows calculated at 12 noon on December $21^{\text {st }}$ (winter solstice). Surrounding vineyards considered in the simulations are shown in the background. 
$0.50 \mathrm{~m}$ wide $\times 0.06 \mathrm{~m}$ thick with a $0.55 \mathrm{~m}$ step. Solutions (D) and (E) have been designed to provide the same amount of shade at both the summer and winter solstices. Finally, a further solution (F) has been considered which has the same distribution of openings as (A) and a total glazed area equal to that of the south front. All the façade configurations considered have been designed on the basis of standard solutions that are technically feasible and that are available on the market. Each of these designs has been translated into a 3-dimensional model in which the optical properties of internal and external surfaces of the buildings have been defined, as reported in Table 1. The finishing materials have been selected on the basis of the outcomes of analyses performed by the authors on a significant sample of farm wineries in the study territory (Corzani et al., 2010).

The analysis was carried out with the Radiance Lighting Simulation and Visualization System (Hussain and Amneh, 2010; Greivulis and Inanici, 2008), using the Ecotect interface with climate data containing specific information about the site (longitude $11.7^{\circ}$, latitude $44.3^{\circ}$, WGS84) and the direct and diffuse radiation (US Department of Energy, 2012). The most widely recognised static and dynamic performance parameters were used in the analysis:

- the average daylight factor (ADF), i.e. the ratio of total daylight flux incident on the working plane to the area of the working plane, expressed as a percentage of the outdoor illuminance on a horizontal plane due to an unobstructed CIE Standard Overcast Sky (Naeem and Wilson, 2007). Based on the above, the calculation of ADF is made on a grid of light sensors facing upwards covering the whole analysed area. The grid resolution is $0.5 \times 0.5 \mathrm{~m}$ with height above ground level equal to the work plan. ADF is the main static parameter used to measure the amount of natural light inside a building (Reinhart $e t$ al., 2006);

- the daylight autonomy (DA), i.e. the percentage of the time of analysis in which a minimum illumination of a reference plane is met with only natural lighting (Reinhart et al., 2006);

- the useful daylight illuminances (UDI) (Nabil and Mardaljevic, 2005), i.e. detecting the percentage of the time of analysis in which

Table 1. Properties of finishing materials of the selling and tasting room.

\begin{tabular}{lccc}
\hline Element & Material & Colour RGB & Reflectance \\
Ceiling, walls, floor & Oak wood & $158,105,45$ & 0.45 \\
Windows & $\begin{array}{c}\text { Low-emission } \\
\text { double glass }\end{array}$ & $144,161,161$ & 0.61 \\
\hline Shading systems & Larch wood & $201,169,88$ & 0.67 \\
\hline RGB, red, green, blue. & & &
\end{tabular}

RGB, red, green, blue. illuminance levels are between the threshold of visibility of 100 lux (lx) and of glare of $2000 \mathrm{~lx}$.

UDI has also been used as an indicator of the glare on the horizontal reference plane by assessing the percentage of the time of analysis when the threshold of $2000 \mathrm{~lx}$ has been overcome. Glare indexes such as the unified glare rating and the daylight glare index have not been adopted for this study about natural lighting because they were derived from experiments with artificial glare sources and none were under real daylight conditions (Reinhart and Wienold, 2011).

DA and UDI are valued in the hours and days of potential use: 365 days per year from 8 am to $8 \mathrm{pm}$ (solar time). For the calculation of the DA parameter, $300 \mathrm{~lx}$ on the work plane is taken as the minimum level of illuminance sufficient for a comfortable use of the room [on the basis of the standard UNI EN 12464-1:2004 (IS0, 2004)]. All the abovementioned parameters were assessed with reference to two points at a height of $0.8 \mathrm{~m}$ on the north-south axis of the room, at a distance of 2 $\mathrm{m}$ (1) and $6 \mathrm{~m}(2)$, respectively, from the south façade.

\section{Results and discussion}

The values of the parameters calculated at the two sensor points are shown in Table 2, which also provides information about the spatial variability of the illuminance. The Tregenza formula (Tregenza, 1986) gives an average sky component of approximately $7350 \mathrm{~lx}$ and this allows us to set a minimum value of $4.1 \% \mathrm{ADF}$, corresponding to the desired minimum level of indoor illuminance of $300 \mathrm{~lx}$. Table 2 shows that solutions (B) to (F) satisfy this requirement also in point 2, i.e. in the centre of the room. Although satisfying regulatory requirements, solution (A) does not guarantee the set performance standard. According to ADF, solution (B) provides the most indoor lighting, although with high glare levels for $69 \%$ of the time of analysis. This requires the use of movable shading devices (e.g. venetian blinds, roller blinds, or curtains). However, on the other hand, these limit the visual connection with the outside landscape and the availability of natural light inside the room. Therefore, we have also analysed in detail the performance of this type of movable shading system integrating the façade solution (B), since it has a decisive impact on the internal effective available daylight (Figure 4).

Movable shading devices can be operated either manually, automatically, or via a combination of both. In the case of manually operated blinds, room lighting conditions vary according to the users' behavioural typologies, as underlined by Reinhart et al. (2006). These authors pointed out that the possibility of simulating how an occupant might operate the blinds depends on being able to define behaviour models of the occupants. In the case of a wine tasting area, these behaviours are expected to be extremely variable, as no rigid protocol of activity can be identified

Table 2. Results of the various performance parameters.

\begin{tabular}{|c|c|c|c|c|c|c|c|c|c|c|c|c|}
\hline \multirow{2}{*}{$\begin{array}{l}\text { Envelope version } \\
\text { Sensor point }\end{array}$} & \multicolumn{2}{|c|}{ A } & \multicolumn{2}{|c|}{ B } & \multicolumn{2}{|c|}{ C } & \multicolumn{2}{|c|}{ D } & \multicolumn{2}{|c|}{$\mathbf{E}$} & \multicolumn{2}{|c|}{$F$} \\
\hline & 1 & 2 & 1 & 2 & 1 & 2 & 1 & 2 & 1 & 2 & 1 & 2 \\
\hline $\operatorname{ADF}(\%)$ & 2.6 & 2.6 & 14.2 & 6.4 & 9.4 & 4.8 & 7.5 & 5.8 & 9.9 & 4.6 & 9.7 & 5.5 \\
\hline Time (\%) & & & & & & & & & & & & \\
\hline DA & 69 & 58 & 93 & 87 & 91 & 85 & 93 & 92 & 91 & 84 & 90 & 87 \\
\hline $\mathrm{UDI}<100 \mathrm{~lx}$ & 12 & 15 & 4 & 7 & 6 & 7 & 4 & 3 & 6 & 7 & 5 & 7 \\
\hline $100 \leq \mathrm{UDI} \leq 2000 \mathrm{~lx}$ & 88 & 85 & 27 & 62 & 44 & 85 & 55 & 52 & 41 & 90 & 46 & 77 \\
\hline $\mathrm{UDI}>2000 \mathrm{~lx}$ & 0 & 0 & 69 & 31 & 50 & 8 & 41 & 24 & 53 & 3 & 49 & 16 \\
\hline
\end{tabular}

$\mathrm{ADF}$, average daylight factor; DA, daylight autonomy; UDI, useful daylight illuminances; lx, lux. 
for tasting demonstrations. In the case of automatic control, the movement of venetian blinds is typically based on photocells and/or occupancy sensors, whose control algorithms have to be known in order to run the simulation model. Therefore, also in this case, the variability of the activities expected to be carried out in the considered functional space means it is not possible to define a priori an operational model for the blinds.

For these reasons, in this study case, it was assumed that venetian blinds were manually operated with a passive user, that is to say lowered throughout the year. This assumption allowed us to consider the maximum effects of the blinds against glare in the design model independently of possible decision-making of manual operators or algorithms of automatic systems. Despite the presence of the shading systems, the resulting illuminance values for this case (solution B integrated with movable shading devices) showed that glare occurs for $53 \%$ of the time of analysis at sensor point 1 and for $10 \%$ of the time of analysis at sensor point 2 .

The DA parameter reported in Table 2 shows that none of the solutions from (B) to (F) need to use electricity for interior lighting for over $84 \%$ of the time of analysis. This highlights the fact that the façade solution (A) is that with the highest energy consumptions related to interior lighting. On the other hand, we found that there is no glare (UDI>2000 lx) for solution (A), and the maximum inner illuminance over the time of analysis is approximately $700 \mathrm{~lx}$. Moreover, DA values specify that (D) is the most advantageous solution.

Figure 5 shows the levels of illuminance calculated as the product of ADF and the average sky component along the north-south axis with different distances from the southern wall. A comparison of the solutions for the fixed blinds, designed to achieve the same shading factor both at the summer and winter solstices, shows that the fixed vertical blinds (E) allow greater illuminances to up to half of the room; however, at a higher distance from the south wall, the fixed horizontal shading system (D) ensures better lighting. Figure 5 shows that (F) and (D) both offer the most effective solutions. In addition, (F) would ensure higher illuminance levels than the target value along the entire axis while at the same time limiting glare (Figures 5 and 6). Thus, the analysis carried out shows that, overall, (D) and (F) are the most suitable. It should, however, be noted that an envelope with windows on all the fronts may have problems of heat loss and may severely limit furnishing options.
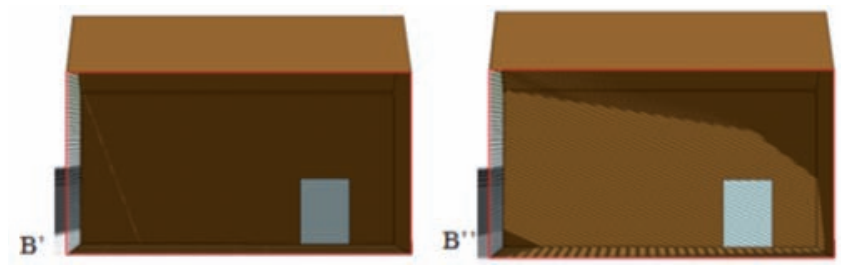

Figure 4. Longitudinal sections of the façade solutions (B) integrated with movable venetian blinds with shadows calculated at 12 noon on June $21^{\text {st }}$ (summer solstice) (B') and on December $21^{\text {st }}$ (winter solstice) (B”).

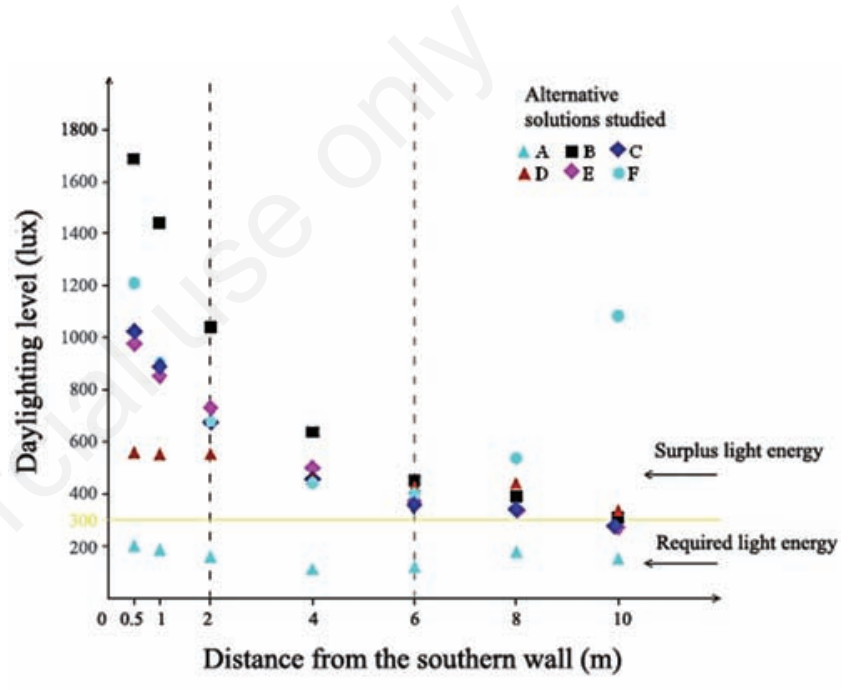

Figure 5. Illuminance values along the north-south axis at $0.80 \mathrm{~m}$ above floor level.
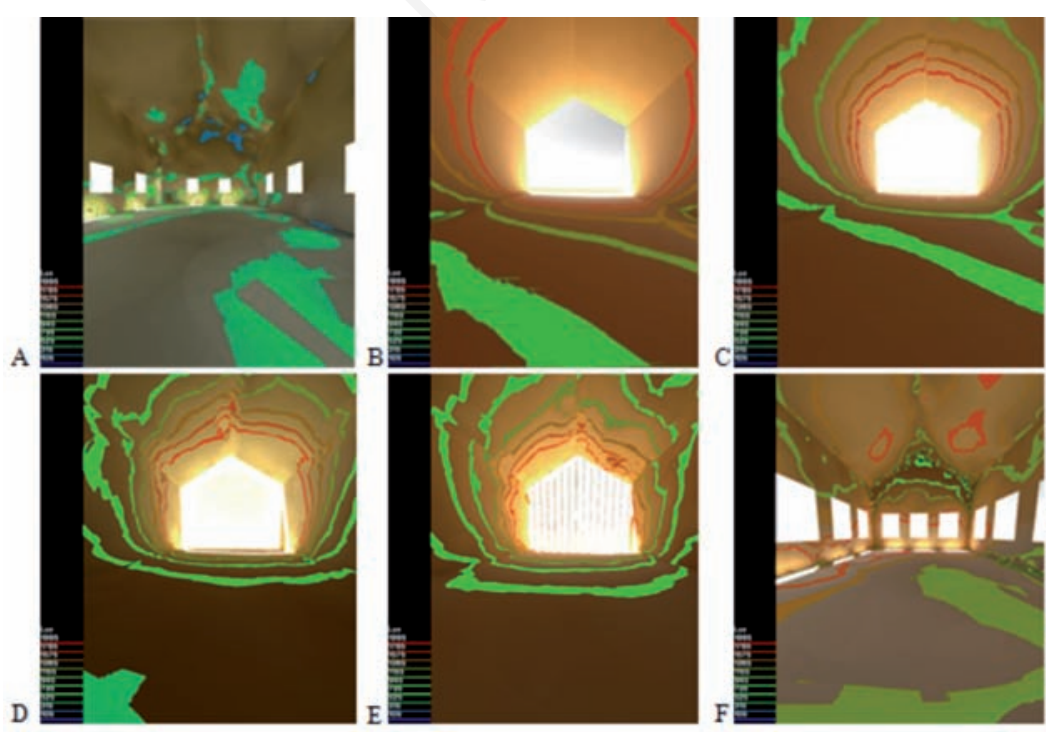

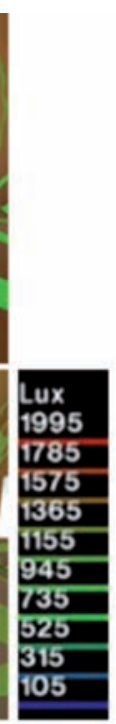

Figure 6. 3D diagrams of the indoor illuminance calculated for each of the 6 solutions at 12 noon on June $21^{\text {st }}$ (summer solstice). 


\section{Conclusions}

The study benchmarked the performance of different window systems for the building portion designated for tasting activities of a farm winery in the Emilia-Romagna region, Northern Italy, in terms of optimisation of natural lighting to improve visual comfort and reduce energy consumption. The results demonstrate the appropriateness of the solutions involving south façade glazing with appropriate screening systems, and, at the same time, the need for further studies to investigate the performance of solutions with windows distributed on several fronts. These could be analysed with reference to different size and distribution possibilities. The research also highlighted the utility of daylighting analysis in the envelope design of a specific functional unit of the wine farm. Further investigation should be directed to other functional areas, also including careful assessment of heat balance in order to achieve integrated design solutions.

\section{References}

Aghemo C., Pellegrino A., Lo Vers V.R.M. 2008. The approach to daylighting by scale models and sun and sky simulators: a case study for different shading systems. Build. Environ. 43:917-27.

Breitenbach J., Lart S., Langle I., Rosenfield J. 2001. Optical and thermal performance of glazing with integral venetian blinds. Energ. Buildings. 33:793-803.

Chang-Sung K., Seung-Jin C. 2011. Daylighting simulation as an architectural design process in museums installed with tolights. Build. Environ. 46:210-22.

Commonwealth of Australia. 2003. A guide to energy innovation in Australian wineries. Energy efficiency and best practices. Available from: http:/www.ret.gov.au/energy/Documents/best-practice-guides/ energy_bpg_wineries.pdf

Corzani V., Benni S., Torreggiani D., Tassinari P. 2010. Le cantine nelle aziende agricole, da "machines à produire" a elementi di attrazione nel paesaggio. Architettura del Paesaggio. 5:1-5.

Greivulis Z., Inanici M. 2008. Composing with light: an inside-out evaluation of the role of intuition and simulation throughout the design process. Proc. PLEA 25th Conf. Passive and Low Energy Architecture, Dublin, Ireland.

Hussain H.A., Amneh H.A. 2010. Assessment of building façade performance in terms of daylighting and the associated energy consumption in architectural spaces: vertical and horizontal shading devices for southern exposure facades. Energ. Convers. Manage. $51: 1592-9$

ISO (International Organization for Standardization). 2004. Light and lighting. Lighting of work places. Part 1: Indoor work places - UNI EN 12464-1:2004. International Organization for Standardization Publications, Geneva, Switzerland.

Khana S., Hanjrab M.A. 2009. Footprints of water and energy inputs in food production, global perspectives. Food Policy. 34:130-40.

Nabil A., Mardaljevic J. 2005. Useful daylight illuminance: a new paradigm to access daylight in buildings. Lighting Res. Tecnol. 37:41-59.

Naeem M., Wilson M. 2007. A study of the application of the BRE Average Daylight Factor formula to rooms with window areas below the working plane. Proc. PALENC. 2:682-6.

Niccolucci V., Galli A., Kitzes J., Pulselli R.M., Borsa S., Marchettini N. 2008. Ecological footprint analysis applied to the production of two Italian wines. Agr. Ecosyst. Environ. 128:162-6.

Oberfeld D., Hecht H., Allendore U., Wickelmaier F. 2009. Ambient lighting modifies the flavor of wine. J. Sens. Stud. 24:797-832.

Pereza Y.V., Guedi Capeluto I.G. 2006. Climatic considerations in school building design in the hot-humid climate for reducing energy consumption. Appl. Energ. 86:340-8.

Reinhart C.F., Herkel S. 2000. The simulation of annual daylight illuminance distributions - A state-of-the-art comparison of six RADIANCE-based methods. Energ. Buildings. 32:167-87.

Reinhart C.F., Mardaljevic J., Rogers Z. 2006. Dynamic daylight performance metrics for sustainable building design. Leukos. 3:1-25.

Reinhart C.F., Wienold J. 2011. The daylighting dashboard - A simulation-based design analysis for daylit spaces. Building Environ. 46:386-96.

Tassinari P., Galassi S., Benni S., Torreggiani D. 2011. The built environment of farm wineries: an analysis methodology for defining meta-design requirements. J. Agricult. Eng. 2:25-31.

Tassinari P., Paolinelli, G., Benni, S., Torreggiani, D. 2010. Design of green areas for the promotion of agriculture: a study case of vinegrowing and wine-producing farm. Acta Hort. 881:381-4.

Tassinari P., Torreggiani D., Benni S., Dall'Ara E. 2013. Landscape quality in farmyard design: an approach for Italian wine farms. Landscape Res. [In press].

Torreggiani D., Benni S., Corzani V., Tassinari P., Galassi S. 2011. A meta-design approach to agroindustrial buildings: a case study for typical Italian wine productions. Land Use Policy. 28:11-8.

Tregenza P.R. 1986. Measured and calculated frequency distributions of daylight illuminance. Lighting Res. Technol. 18:71-4.

U.S. Department of Energy. 2012. Building design. Available from: http://energy.gov/public-services/building-design 